\title{
AN UNFAMILIAR SOCIAL NORM RAPIDLY PRODUCES FRAMING EFFECTS IN AN ECONOMIC GAME
}

\author{
L. CRONK ${ }^{1}$ AND H. WASIELEWSKI \\ Department of Anthropology \& Center for Human Evolutionary Studies \\ Rutgers University
}

\begin{abstract}
We framed trust games played by Americans with the concept of osotua, a Maasai label for a type of gift-giving relationship shaped by feelings of mutual respect, restraint, and responsibility. As a control, one third of the participants $(\mathrm{N}=70)$ read a text unrelated to social life. The other two-thirds $(\mathrm{N}=140)$ read about Maasai and osotua. Half of those who read about Maasai and osotua played unlabeled trust games, while the other half played trust games labeled "the Osotua game.” Results are similar to those previously obtained from trust games played by Kenyan Maasai with and without osotua framing. As in Kenya, transfers were lower in the osotua-framed games than in the games framed by the Maasai text but not the osotua label. As in Kenya, the relationships among transfers and expected returns in the games framed by the Maasai text but not the osotua label reflect the tit-for-tat logic of reciprocity, while osotua-framed games do not show that pattern. These findings have implications for the experimental game method and for the study of the relationship between culture, social norms, and social behavior.
\end{abstract}

Keywords: experimental games, trust game, framing, reciprocity, cooperation, social norms, Maasai, osotua

\section{INTRODUCTION}

A large body of literature exists on the ability of framing cues and their associated scripts and schemata to influence behavior (e.g., BARTLETT 1932; BATESON 1972; TVERSKY and KAHNEMANN 1981). In simple terms, the idea is that people follow scripts or schemata that are triggered by cues associated with particular circum-

\footnotetext{
${ }^{1}$ Corresponding author: Department of Anthropology, Rutgers University, 131 George St., New Brunswick, NJ 08901-1414, USA, Fax: 732-932-1564

Email: lcronk@anthropology.rutgers.edu.
} 
stances. Knowing how to conduct oneself in a specific kind of social setting, whether it be a restaurant, a church, or a classroom, requires an ability to detect relevant framing cues and some knowledge of the scripts and schemata associated with them. Terms such as "buy," "sell," and "money," for example, suggest a commercial transaction. Additional terms such as "order," "bill," and "tip" restrict the possibilities to a particular kind of commercial transaction: Eating in a restaurant. Like the simple heuristics shown by bounded rationality theorists to improve individual decision-making when information is limited (e.g., GIGERENZER and TODD 2000), frames serve as social heuristics that allow us to work together as teams more effectively (BACHARACH 2006; SUGDEN 1993; VAN HUYCK et al. 1995).

An appreciation of framing effects has been important for our understanding of how people play experimental economic games (BICCHIERI 2006; ELLIOTT and HAYWARD 1998; GINTIS 2007; HAGEN and HAMMERSTEIN 2006; HEINTZ 2005). In a few instances, locally salient frames have been noted by the participants themselves or by people familiar with the specific ethnographic setting in which a study was conducted. For example, Ensminger's Orma participants spontaneously used the Swahili word harambee, which Kenyans use to refer to public goods projects and associated fund-raising, to identify a public goods game (ENSMINGER 2000, 2004). TRACER (2003) noted that his Highland New Guinea participants' familiarity with competitive gift-giving systems helps explain their unusual behaviors in the ultimatum game. In such systems, giving large gifts raises the giver's status relative to that of the receiver, and his participants tended both to make and to reject high offers.

In many other studies, frames have been deliberately created by researchers in order to explore their effects on game-playing behaviors. For example, BURNHAM et al. (2000) found that referring to the other player as either "partner" or "opponent" had a significant effect on how people played an extensive form trust game. Similarly, PILLUTLA and CHEN (1999) found that people contributed more to a public goods game framed as a community social event than to one framed in economic terms. Recently, LESOROGOL (2007) found that Samburu playing dictator games framed by a local food-sharing norm tended to make lower offers than those playing unframed games, a pattern of behavior consistent with that norm. It is reasonable to conclude that participants in studies like these interpret experimental games in terms of both the broader cultural contexts in which they live and cues provided by researchers.

The present study was inspired by a framing study conducted by the senior author (CRONK 2007) that will be described more fully in the next section. We began with two research questions. The first was whether the framing effects observed in that and other studies require long term exposure to cultural norms. We hypothesized that even brief exposure to an unfamiliar social norm would have an impact on how people play an experimental economic game. That hypothesis emerged from two related observations. First, because an ability to coordinate one's behavior with others (SCHELLING 1960) is likely to have been adaptive during human evolu- 
tion, we may have a propensity to seek out and follow social coordination norms. Second, we may also have an evolved propensity to conform readily to local patterns of behavior when we find ourselves in unfamiliar circumstances (BOYD and RICHERSON 1985). Given the lack of preexisting frames or guidelines for how to behave in such situations, participants in experimental games may be particularly susceptible to suggestions made by researchers about relevant frames and associated scripts. This led us to our second question: Can brief exposure to an unfamiliar social norm by itself influence behavior in an experimental game, or is it necessary to include a cue that explicitly frames the game in terms of the norm?

From these questions we developed a general hypothesis that American game playing behavior in the Maasai-text and osotua frames will correspond to that seen in Kenya in the unframed and osotua-framed games. From that hypothesis we derived four more specific predictions: (1) amounts given by all players will be lower in the osotua-framed games than in the Maasai-text games; (2) amounts given by Player One will be lower in the osotua-framed games than in the Maasai-text games; (3) amounts given by Player Two will be lower in the osotua-framed games than in the Maasai-text games; (4) game playing behavior in the Maasai-text games will show patterns consistent with the tit-for-tat logic of reciprocity, while the osotua-framed games will not.

\section{BACKGROUND: THE OSOTUA CONCEPT AND MAASAI TRUST GAME PLAY}

CRONK (2007) describes a study conducted among Maasai in Kenya’s Mukogodo area (CRONK 2004) in which 25 trust games framed with a locally salient economic concept were contrasted with 25 games played with no deliberate framing. The concept used to frame the game is osotua. Osotua literally means umbilical cord, but Maasai use it metaphorically to refer to certain kinds of gift-giving relationships. Osotua relationships are shaped by feelings of mutual respect, restraint, and responsibility. Osotua relationships usually begin with a request for a gift or favor. Such requests can arise only from genuine need, and the gift or service given in response should never exceed that need. Gifts are not seen as payments and do not result in debt or any other obligation to repay. Indeed, it is considered inappropriate to use words like "debt" (sile) and "pay" (alak) when discussing osotua relationships. Although osotua relationships do involve reciprocal obligations to help if asked, the actual flow of goods and services may be mostly or entirely one way, if that is where the need is greatest. Although osotua partners are normally on friendly terms, osotua is not simply a Maasai word for friendship. Osotua is a formal relationship involving specific obligations and expectations not associated with simple friendships, for which there is another term. Nor is osotua merely an informal, metaphorically colorful way of asking for aid. Osotua partners take their relationships and the obligations they entail very seriously. 
Although the trust game has some characteristics that are quite unlike osotua relationships (e.g., the immediacy of the exchange), it was used because its giveand-take structure resembles such relationships more than, for example, the dictator or ultimatum games. All Maasai players were given standard instructions on how to play the trust game. The only variation in the instructions was one sentence included in training sessions for the framed but not the unframed games: "This is an osotua game.” That minimal framing resulted in several contrasts between osotuaframed games and unframed games. In keeping with the emphasis in osotua relationships on restraint, respect, and responsibility, amounts given by both players as well as the amounts that first players expected to receive in return were all lower in the framed than in the unframed games. Furthermore, a positive correlation was found between amounts given and amounts expected in return in games played without deliberate rhetorical framing, suggesting that players in the unframed games were invoking the logic of trust, investment, and tit-for-tat reciprocity that is usually assumed by researchers using the trust game. In the osotua-framed games, in contrast, no relationship was found between amounts given and amounts expected in return. In osotua-framed games but not in unframed games, amounts given by the first player and proportional amounts returned by the second player were negatively correlated, suggesting that the osotua framing shifts game play away from the logic of investment and towards the mutual obligation of osotua partners to respond to one another's genuine needs, but only with what is genuinely needed. The correspondence between the characteristics of osotua relationships and the way the games were played when framed with that concept is all the more striking when one considers the differences between such relationships and the structure of the trust game. For the purposes of the present study, it is important that the osotua norm is not simply a matter of tit-for-tat, you-scratch-my-back-and-I'll-scratchyours reciprocity. This allows us to see whether even a norm unlike any with which our participants are likely to have had previous experience can still influence their behavior after only brief exposure to it.

\section{METHODS}

\subsection{Participants}

We used posters, advertisements in the Rutgers campus newspaper, and announcements in large classes to recruit 210 participants. 95 participants were male (mean age $=19.98$ years, $\mathrm{SD}=3.27$ years) and 115 were female (mean age $=19.63$ years, $\mathrm{SD}=2.33$ ). All participants signed an informed consent form approved by Rutgers' Office of Research and Sponsored Projects and received a \$5 show-up fee in addition to whatever they made from the game. 


\subsection{Design}

In the Kenyan study, all participants had access to the osotua framework from their own experience as Maasai, but its impact on game-playing behavior only became evident when it was used to frame the games. This suggests that, at least in some circumstances, minimal framing may be enough to produce dramatic effects on behavior. To explore how difficult or easy it is to produce such effects, we gave American participants brief training in the osotua concept and other aspects of Maasai culture and then had them play the trust game. As in Kenya, half of the games were framed with the osotua concept and half were not. Those two sets of games were compared with a third in which a dummy frame was used that had nothing to do with Maasai or osotua.

\subsection{Procedure}

Two slightly different versions of the trust game have been used by researchers. Both are two-player games in which the first player is given some amount of money and allowed to give any portion of it, or none at all, to the second player, and keep whatever remains. The experimenter triples the amount given to the second player, who can return any portion of his enlarged stake to the first player, keeping whatever remains. In the simplest version of the game, only the first player receives an initial endowment. A slight modification of the game is to give both players equal initial endowments (BARR 2004; LESOROGOL 2004). Endowing the second player as well as the first is intended to reduce the chance that the amount the first player decides to give to the second player reflects notions of fairness and to increase the chance that it reflects feelings of trust. We used the version in which both players are given an initial endowment so that the results would be comparable with those obtained in Kenya. In the experimental game literature, the first player is often called the "investor" and the second player the "trustee." Because the Kenyan study showed that these labels are not appropriate for all frames, in this article we refer to them instead simply as Player One and Player Two.

210 individuals played the game, randomly and evenly distributed among the three frames and two player types. Each individual participated only once. Participants played the game via a web-based computer interface. They first saw one of two web pages consisting of about 1,600 words of text and several pictures followed by ten multiple choice questions about the material (these materials are provided in the appendix). Neither text mentioned any games. The questions that appeared alongside the text were included to encourage participants to read carefully, not to test their understanding of the material. Participants were required to answer all ten questions in order for the computer to advance to the next phase of the experiment. Participants in the dummy frame $(\mathrm{N}=70)$ read a page describing some facts about meteorology followed by ten multiple choice questions about the read- 
ing. We used a dummy frame rather than no frame at all to control for the possibility that simply reading some text and answering questions about it might have an impact on how people play the game. We chose meteorology as the topic for that frame because it seemed less likely than other possible topics (e.g., animal behavior) to trigger social cognition mechanisms. All other participants $(\mathrm{N}=140)$ read a page describing Maasai culture in general and the osotua concept in particular.

After participants answered all ten multiple choice questions, they saw a screen explaining how to play the trust game. All of the participants in the dummy frame $(\mathrm{N}=70)$ and half of those who had read about Maasai and osotua $(\mathrm{N}=70)$ saw instructions that were labeled simply "Game instructions." Half of the participants who had read about the Maasai and osotua $(\mathrm{N}=70)$ saw exactly the same instructions as did all other players except that theirs were entitled "The Osotua game" and included the sentence "This game is called the osotua game." Thus, participants who read about the Maasai but whose game was not labeled "The Osotua game" were in a position similar to that of Maasai who played the unframed game, i.e., familiar with the osotua concept but not prompted to use it as a frame for the game. Participants who read about the Maasai and who were told that the game was called "The Osotua game" were in a position analogous to that of Maasai who played the osotua-framed games. The dummy frame provides a baseline for behavior in the trust game in this particular setting.

The game interface was interactive, allowing participants to see the effect of different allocations on themselves and the other player before making a decision regarding how to allocate their funds. Those in the role of Player One were also asked how much they expected to receive in return from Player Two. One participant did not provide a figure for expected return. Most participants took about 20 to 30 minutes to complete the study. All participants in the role of Player One started out with $\$ 10$ to use in the game. Participants in the role of Player Two started out with $\$ 10$ plus three times the amount given to them by their corresponding Player One. Allocations could be made in $\$ 1$ increments. The computer assigned those in the role of Player Two randomly to those in the role of Player One, while always keeping the framing the same for both players in a particular game. Players were anonymous to each other.

In addition to game play, we also recorded all participants' sexes, ages, and question responses. Modal scores on the multiple choice questions were $100 \%$ across all frames and both types of players. Because multivariate OLS models showed no significant effects for either these variables or their interactions with the frames on amounts given or expected in return, they are not considered in the analyses given below. 


\section{RESULTS}

Data were analyzed using SPSS 14.0 and 16.0. Results and associated statistical tests are given in Tables 1-3 and in Figures 1-5. Two-tailed tests are used except when we have directional predictions, when we instead use one-tailed tests. To facilitate comparisons between Kenyan and US game play, we multiply amounts given in the US games by ten. Because the amounts involved in the games mean very different things to the two groups of players, we use ranks rather than raw amounts when comparing between countries. In absolute terms, ten dollars is much more money than 100 Kenyan shillings, which was worth about \$1.33 when the Kenyan games were played. However, 100 shillings is worth much more to a typical Kenyan than ten dollars is to a typical American. While 100 shillings is a typical daily wage for unskilled labor in rural Kenya, $\$ 10$ is barely enough to buy lunch in most of the US. Amounts given and expected in return were ranked within each country and player type but across experimental treatments. US games played in the dummy frame were left out of this ranking procedure because no comparable treatment existed in the Kenyan study. Fractional ranks were used rather than simple ranks because of the different sample sizes in the two settings. Tied ranks were given mean scores.

Table 1. Regression coefficients. Country and treatment were coded as dummy variables (Kenya $=0, \mathrm{US}=1$; unframed games in Kenya and Maasai-text framed games in the US $=0$, osotua-framed games in both countries $=1$ ). Dependent variables are all fractional ranks within countries ad player type

\begin{tabular}{|c|c|c|c|c|c|c|}
\hline \multirow[b]{2}{*}{$\begin{array}{c}\text { Dependent } \\
\text { variable }\end{array}$} & \multicolumn{3}{|c|}{ Country } & \multicolumn{3}{|c|}{ Treatment } \\
\hline & $\begin{array}{l}\text { Unstandardized } \\
\text { regression } \\
\text { coefficient } \\
\text { (standard error) }\end{array}$ & $\begin{array}{c}\text { Standardized } \\
\text { regression } \\
\text { coefficient }\end{array}$ & $\begin{array}{c}\mathrm{p}- \\
\text { value }\end{array}$ & $\begin{array}{l}\text { Unstandardized } \\
\text { regression } \\
\text { coefficient } \\
\text { (standard error) }\end{array}$ & $\begin{array}{c}\text { Standardized } \\
\text { regression } \\
\text { coefficient }\end{array}$ & $\begin{array}{c}\mathrm{p}- \\
\text { value }\end{array}$ \\
\hline All transfers & $-.143(3.734)$ & -.002 & .970 & $-9.313(3.681)$ & -.162 & .012 \\
\hline $\begin{array}{l}\text { Player One } \\
\text { transfers }\end{array}$ & $-.003(.051)$ & -.005 & .956 & $-.136(.051)$ & -.241 & .008 \\
\hline $\begin{array}{l}\text { Player One } \\
\text { expectations }\end{array}$ & $-.004(.052)$ & -.006 & .947 & $-.105(.052)$ & -.185 & .045 \\
\hline $\begin{array}{l}\text { Player Two } \\
\text { transfers }\end{array}$ & $-.003(.052)$ & -.005 & .956 & $-.140(.051)$ & -.246 & .007 \\
\hline
\end{tabular}

Figures 1 and 2 show amounts given in the US games. The dummy frame is included to provide a baseline for American behavior in this particular setting and game. As in Kenya, Player One and Player Two both tended to give less in the osotua frame. We ran linear regressions on fractional ranks of four dependent variables (all transfers, Player One transfers, Player One expected returns, and Player Two transfers), using country (Kenya/US) and treatment (unframed in Kenya; Maasaitext in the US/osotua in both countries) as dummy independent variables (Table 1). 
In all cases, the regression coefficient for country is insignificant while the regression coefficient for treatment is both negative, reflecting osotua's depressive effect on amounts given and expected, and statistically significant.

$\square$ Dummy frame $\mathbb{Q}$ Maasai text, unframed $\square$ Maasai text, osotua-framed

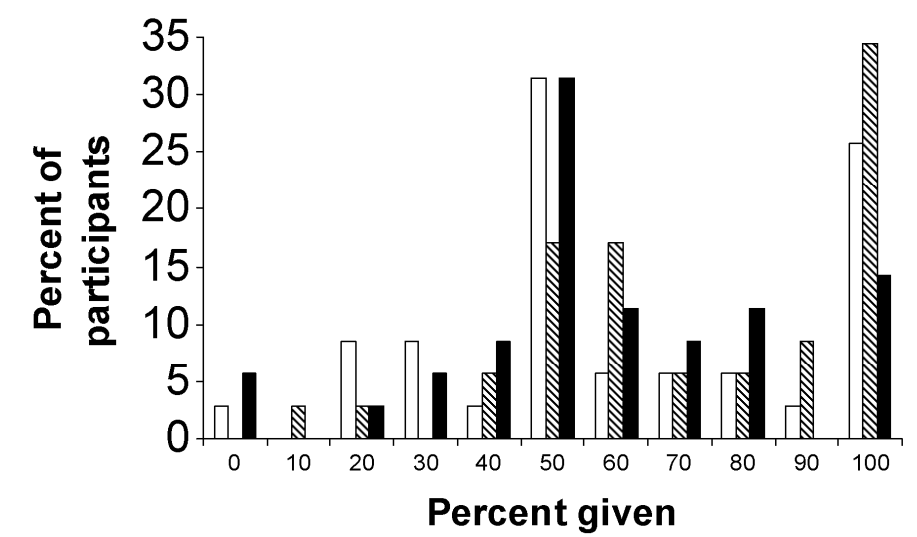

Figure 1. Percentage of player's stake given to the other player, Player One

$\square$ Dummy $\mathbb{N}$ Maasai text, unframed $\square$ Maasai text, osotua-framed

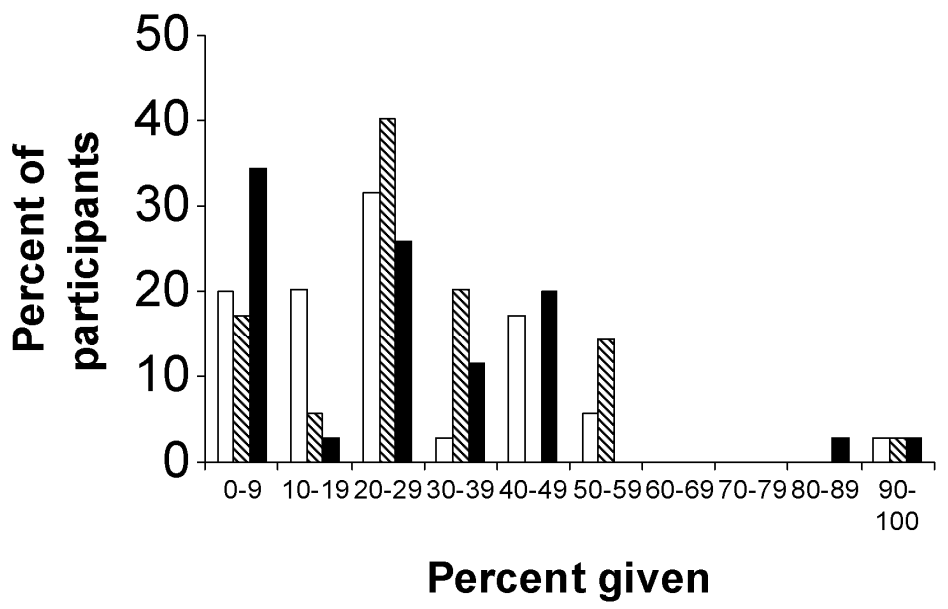

Figure 2. Percentage of player's stake given to the other player, Player Two 
In Figure 3 and in Tables 2 and 3, we examine differences between mean amounts given both within and between countries and treatments. Comparisons within treatments but between countries (Table 2) show no particular pattern and yield no statistically significant results. Comparisons within countries but between treatments, in contrast (Table 3), all show the depressive effect of the osotua frame, and several of them reach conventional levels of statistical significance. The osotua frame is associated with lower mean proportions given by all players in both Kenya $(t=2.062, \mathrm{p}=0.021)$ and the US $(t=1.768, \mathrm{p}=0.040)$. Similarly, the osotua frame is associated with lower mean amounts given by Player Two in both Kenya $(t=$ $2.545, \mathrm{p}=0.007)$ and the US $(t=1.764, \mathrm{p}=0.041)$. The osotua frame is associated with lower mean amounts given by Player One in both countries, as well, but the difference reaches conventional levels of statistical significance only in the US $(t=$ $2.403, \mathrm{p}=.001)$.

Table 2. Comparisons of means within treatments and between countries. Means were calculated from fractional rank scores within each country. "Maasai" refers to the unframed games in Kenya and to the games framed by the Maasai text but not by the "osotua game" label in the US

\begin{tabular}{lccrc}
\hline Variable and treatment & $\begin{array}{c}\text { Mean (s.d.), } \\
\text { Kenya }\end{array}$ & $\begin{array}{c}\text { Mean } \\
\text { (s.d.), } \\
\text { US }\end{array}$ & $t$ & p-value \\
\hline Proportion given by all players, Maasai & $.564(.287)$ & $.541(.290)$ & .438 & .662 \\
Proportion given by all players, osotua & $.446(.279)$ & $.466(.284)$ & -.394 & .694 \\
Player One transfers, Maasai & $.560(.278)$ & $.588(.280)$ & -.371 & .712 \\
Player One transfers, osotua & $.460(.281)$ & $.427(.272)$ & .455 & .651 \\
Player Two transfers, Maasai & $.611(.286)$ & $.555(.280)$ & .756 & .453 \\
Player Two transfers, osotua & $.409(.244)$ & $.459(.294)$ & -.698 & .488 \\
\hline
\end{tabular}

Table 3. Comparisons of means within countries and between treatments. Kenyan players started with 100 Kenyan shillings in ten-shilling coins and US players started with 10 US dollars divisible in one dollar increments. To facilitate comparisons between the two countries, the US data have been multiplied by ten. One-tailed tests are used because of the directionality of the hypothesis

\begin{tabular}{lrrrr}
\hline Variable and country & $\begin{array}{c}\text { Mean (s.d.), } \\
\text { unframed games } \\
\text { (Kenya) and } \\
\text { Maasai-text } \\
\text { frame (US) }\end{array}$ & $\begin{array}{c}\text { Mean (s.d.), } \\
\text { osotua frame }\end{array}$ & $t$ & $\begin{array}{c}\text { p- } \\
\text { value } \\
\text { (one- } \\
\text { tailed) }\end{array}$ \\
\hline Proportion given by all players, & $.35(.191)$ & $.28(.162)$ & 2.062 & .021 \\
Kenya & $.50(.319)$ & $.41(.295)$ & 1.768 & .040 \\
Proportion given by all players, US & $38.00(21.602)$ & $30.80(19.983)$ & 1.223 & .114 \\
Player One transfers, Kenya & $72.57(25.935)$ & $57.71(25.792)$ & 2.403 & .001 \\
Player One transfers, US & $69.20(41.525)$ & $45.60(20.632)$ & 2.545 & .007 \\
Player Two transfers, Kenya & $90.86(68.787)$ & $64.00(58.118)$ & 1.764 & .041 \\
Player Two transfers, US & & & & \\
\hline
\end{tabular}


In the Kenyan study, those in the role of Player One who gave more expected more in return, but only in the unframed games. Figure 4 shows that this pattern is repeated in the American data. Also as in Kenya, there is a positive relationship between amounts given by Player One and amounts returned by Player Two in the Maasai-text games but not in the osotua games (Figure 5). Both of these patterns suggest that while the logic of tit-for-tat reciprocity is at work among players in the unframed and Maasai-text games, that logic is replaced by something else when the games are framed with the osotua concept.

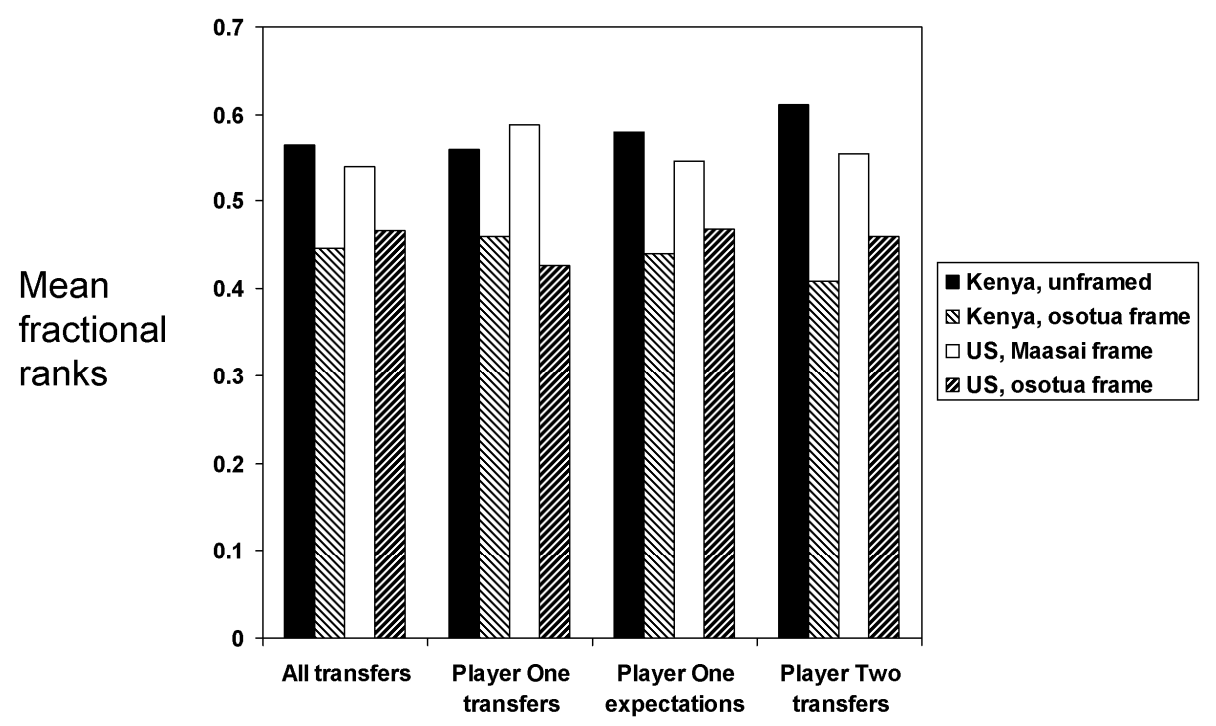

Figure 3. Comparison of mean fractional ranks within and between countries and treatments. Statistical tests are provided in Tables 2 and 3

We also compared means for all transfers, Player One transfers, and Player Two transfers between the two experimental frames and the dummy frames (Table 4). None of the differences is statistically significant. However, it is interesting to note that in each case the mean for the dummy frame lies between the means for the two experimental frames. This suggests that the experimental frames are pulling game playing behavior in opposite directions. The Maasai-text frame appears to encourage generosity and trust. Adding the osotua label reduces amounts given to levels lower than, though statistically indistinguishable from, the amounts given in the dummy frame. 
Table 4. Comparisons of means in the dummy frame and other US frames

\begin{tabular}{|c|c|c|c|c|c|c|c|}
\hline \multirow[b]{2}{*}{ Variable } & \multirow[b]{2}{*}{ Mean (s.d.) } & \multicolumn{3}{|c|}{ Maasai } & \multicolumn{3}{|c|}{ Osotua } \\
\hline & & Mean (s.d.) & $t$ & $\begin{array}{c}\mathrm{p}^{-} \\
\text {value }\end{array}$ & Mean (s.d.) & $t$ & $\begin{array}{c}\mathrm{p}- \\
\text { value }\end{array}$ \\
\hline All transfers & $.42(.313)$ & $.50(.319)$ & -1.482 & .141 & $.41(.295)$ & .245 & .807 \\
\hline $\begin{array}{l}\text { Player One } \\
\text { transfers } \\
\text { Player }\end{array}$ & 61.43 (29.119) & 72.57 (25.935) & -1.691 & .095 & $57.71(25.792)$ & .565 & .574 \\
\hline transfers & $65.71(58.626)$ & 90.86 (68.787) & -1.646 & .104 & $64.00(58.118)$ & .123 & .903 \\
\hline
\end{tabular}

\section{DISCUSSION}

The data support our predictions. In the US, amounts given by all players, by those in the role of Player One, and by those in the role of Player Two are all lower in the osotua-framed condition than in the Maasai-text condition. Furthermore, the relationships shown in Figures 4 and 5 between Player One transfers, expected returns, and Player Two transfers are similar for data from both countries.

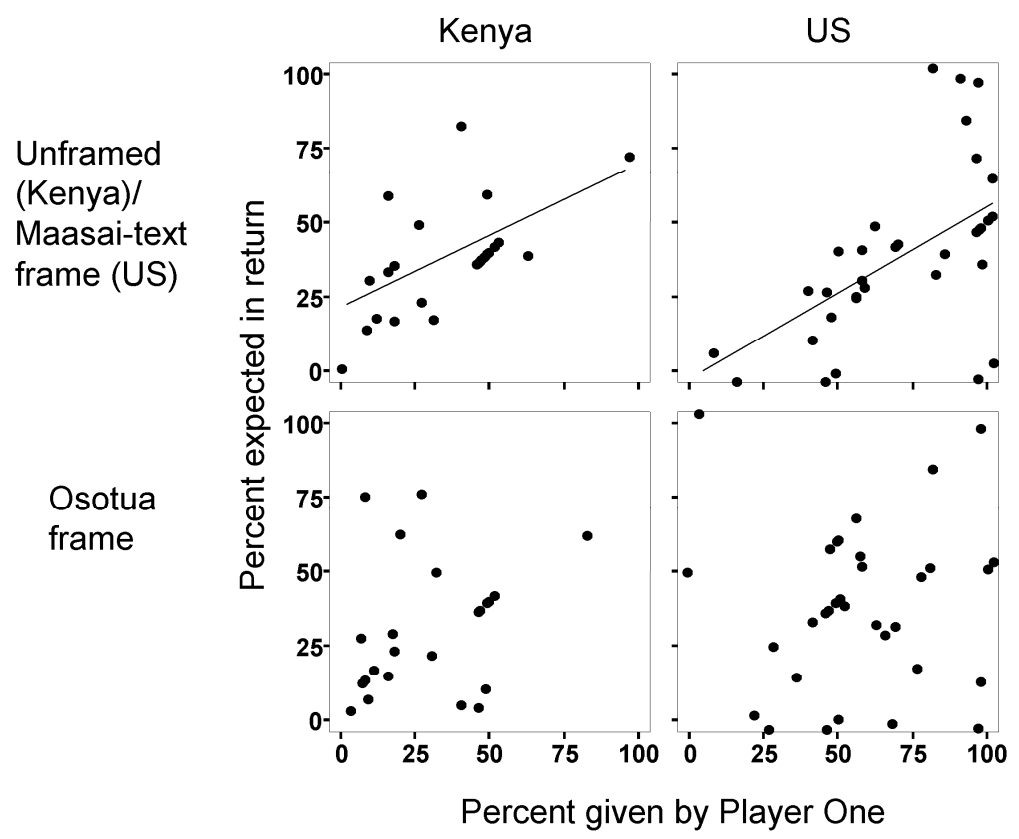

Figure 4. Percentages given by Player One (horizontal axis) and expected in return (vertical axis), in both countries and treatments. Regression lines are shown where they reach conventional levels

of statistical significance: Kenya, unframed: $\beta=0.610, P$ (one-tailed) $=0.0005$, adjusted

$\mathrm{R}^{2}=0.345$; US, Maasai text frame: $\beta=0.542, P$ (one-tailed) $=0.0005$, adjusted $\mathrm{R}^{2}=0.273$;

Kenya, osotua frame: $\beta=0.267, P$ (one- tailed) $=0.099$, adjusted $\mathrm{R}^{2}=0.031$;

US, osotua frame: $\beta=0.047, P$ (one-tailed) $=0.396$, adjusted $R^{2}=-0.029$ 


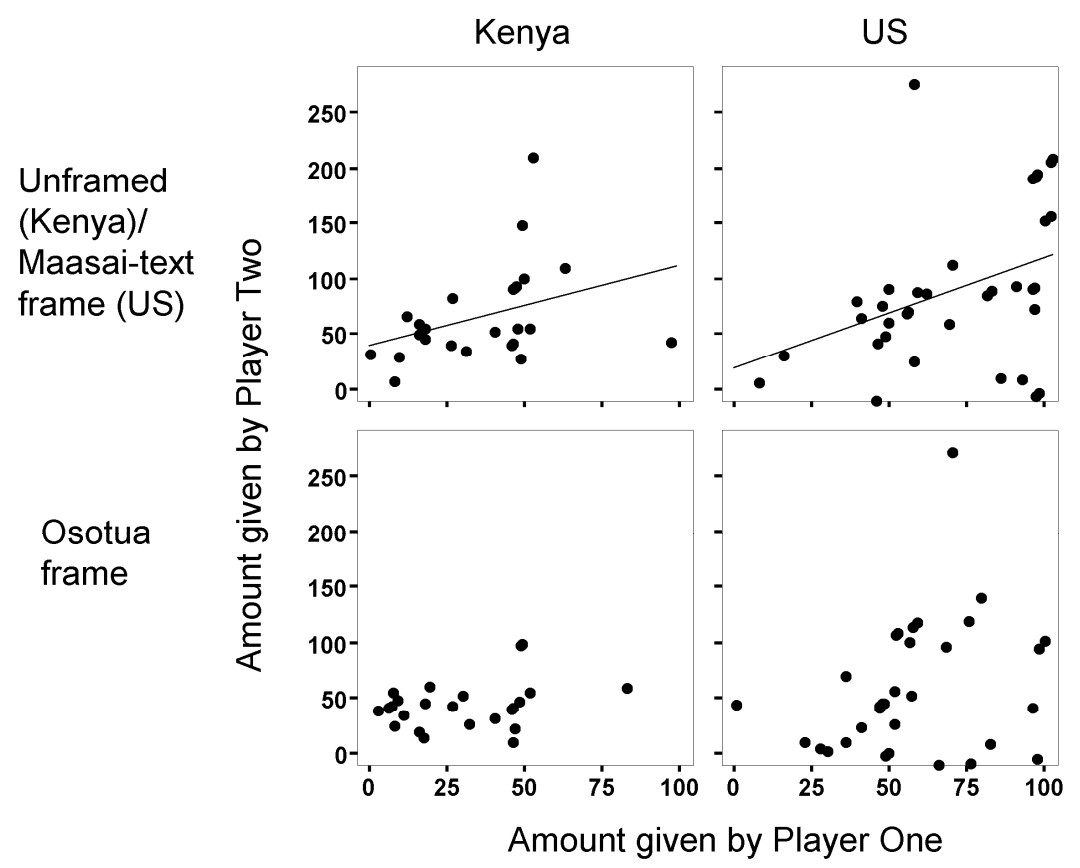

Figure 5. Amounts given by Player One (horizontal axis) and Player Two (vertical axis), in both countries and treatments. Kenyan players started with 100 Kenyan shillings in ten-shilling coins, and US players started with 10 US dollars divisible in one dollar increments. To facilitate comparisons between the two countries, the US data have been multiplied by ten. Regression lines are shown where they reach conventional levels of statistical significance:

Kenya, unframed: $\beta=0.356, P$ (one-tailed) $=0.041$, adjusted $\mathrm{R}^{2}=0.089$;

US, Maasai text frame: $=0.383, P$ (one-tailed) $=0.012$, adjusted $\mathrm{R}^{2}=0.121$;

Kenya, osotua frame: $\beta=0.272, P$ (one- tailed) $=0.095$, adjusted $R^{2}=0.034$;

US, osotua frame: $\beta=0.224, P$ (one-tailed) $=0.098$, adjusted $\mathrm{R}^{2}=0.021$

\subsection{Frames, Norms, and Behavior}

This study, like many earlier ones, demonstrates the ability of frames to shape behavior in economic games and other experimental settings. More specifically, it shows that even brief exposure to an unfamiliar social norm is sufficient to influence participants' behavior and that the addition of framing cues serves to refine the impact of the norm. At a minimum, this underlines how important it is for researchers to pay attention to the frames that their participants may be using, whether those frames are supplied by the researcher or by the participants themselves. By supplying a frame, experimenters can exert some control over how participants approach the task of playing the game (HERTWIG and ORTMANN 2001). 
Obviously, these results do not mean that any of our participants internalized either the osotua norm or anything else that they read about. It is safe to assume that participants were no more likely to establish osotua partnerships with anyone after leaving the lab than they were to use dung to build their houses. The contrasts among our three treatments suggest that our participants sought and used cues regarding the appropriate frame for the game. The generosity shown by those who read about the Maasai and osotua but who were not told that it was "the Osotua game” suggests that simply reading about Maasai social life may be enough to trigger schemata of exchange, such as reciprocity and investment, that are important in American society. However, it is also clear that simply reading the details about osotua relationships included in the Maasai text was not enough to get people to play the game according to the strictures of the osotua norm. This may reflect the important differences between the osotua norm and American cultural norms regarding exchange. Interestingly, getting players to use the osotua norm to shape their behavior requires only one additional cue: The label "The Osotua game."

\subsection{Framing, Scripts, and Demand Characteristics}

In interpreting these results, it is necessary to distinguish between the influence of frames and that of "demand characteristics," i.e., those aspects of the experiment that can be used by participants to anticipate and produce the results participants believe are expected by the experimenter (ORNE 1962). In any experimental situation, participants are aware that their behavior is being used to test hypotheses. Participation in an experiment necessarily entails some acquiescence to experimenter demand in the form of following the format of the testing. The question for determining the presence of demand characteristics is whether the format was such that it interferes with the hypothesized effect of the experimental variable. An explanation of our results based on demand characteristics is unlikely. Our between-subjects design eliminates the possibility that participants could use differences between the conditions to guess the purpose of the study. In addition, participants received monetary payments related to their performance; this focuses participants' attention on their income rather than on the experimenter's happiness (HERTWIG and ORTMAN 2001).

The dummy-framed games are not subject to demand characteristics because the reading passage contained no information about social or economic practices. There are also good reasons to reject a demand characteristic explanation for the patterns seen in the data from the Maasai text games. For the Maasai text condition, the nature of the demand required by the experimenter is unclear. Aside from the osotua concept, the Maasai text did not include any directly relevant information about social reciprocity in Maasai culture. However, participants who read the Maasai text and played the unframed game did not apply the osotua concept to this game play condition. In conjunction with the Kenyan results in the parallel condi- 
tion (CRONK 2007), this result could stem from the lack of correspondence between the structure of the game and the osotua concept. If participants in this condition were seeking to confirm experimental hypotheses, they did not (or could not) do so using the osotua concept in the text, and other directly applicable information about a possible experimental hypothesis was not available to them.

A demand characteristic explanation of the patterns seen in the osotua-framed games is also unlikely. The intent of framing economic games is to influence the way people play the game, so it is not surprising that behavior in the osotua-framed condition was different than behavior under the Maasai-framed condition. What is interesting and of value is the pattern of behavior and the conditions that produced the behavior. With only minimal exposure to the osotua concept, American participants were able to apply these values to their game play, and they did so in a manner that is highly similar to that shown by Kenyan participants. Our intent was not to measure whether behavior changed when games were labeled with the osotua concept, but how it changed. While the osotua frame meets characteristics of demand for changing behavior, as all frames do, it does not meet characteristics of demand for the pattern of behavior produced. Since our hypotheses and our interpretation of the results concern patterns of behavior, that the osotua label meets minimal demand characteristics criteria for changing behavior does not influence these conclusions.

\subsection{Culture and Behavior}

Although a central tenet of anthropology and other social sciences is that culture shapes behavior, we have only a poor understanding of why culture influences behavior powerfully in some circumstances and weakly or not at all in others (CRONK 1999; D'ANDRADE 1992). Studies like this one suggest that an important variable is whether a particular culture trait concerns a behavior that does not need to be coordinated with others or a behavior that provides benefits only if it is coordinated with others. When a culture trait concerns a behavior that does not require social coordination, behavior may be influenced by things other than culture, and discrepancies between culture and behavior may arise. CRONK $(1989,2000,2004)$ has documented such a discrepancy in the realm of parental behavior among the Mukogodo of Kenya. Although they express a preference for boys, Mukogodo parents tend to treat daughters better than sons. Espousing a preference for sons reflects their broader strategy of emulating higher status people who also espouse such a preference. But favoring daughters makes sense reproductively because daughters have better marital and reproductive prospects than sons. Thus, in the context of caring for small children, behaviors may deviate from the stated norm without even the caregivers themselves being aware of the discrepancy.

Culture traits that help coordinate social behavior, in contrast, must have an impact on behavior in order for people to reap the benefits of social coordination. It 
follows that we may be particularly adept at identifying norms and other focal point solutions to coordination problems (SCHELLING 1960) and easily accepting of their impact on behavior. An additional variable that may influence culture's ability to shape behavior is the familiarity or unfamiliarity of the situations in which people find themselves. When exposed to unfamiliar situations, organisms ranging from guppies (LALAND and WILLIAMS 1998) to humans (READER et al. 2007) conform to patterns of behavior displayed by others who may be more familiar with the environment (BOYD and RICHERSON 1985). In the present study, both of these variables are present. The game is a social situation in which participants may benefit from coordinating their behavior with each other. Participating in an experimental game is also an unfamiliar situation for most people, which may increase their sensitivity to framing cues. Assessing the relative importance of familiarity versus social coordination in shaping the relationship between culture and behavior will require studies designed to examine them separately. 


\section{Appendix: FRAMING TEXTS}

(1) Text describing the Maasai and the osotua concept

\section{The Maasai: A brief introduction}

This short presentation will familiarize you with the basic features of Maasai society and culture. After reading it, you will take a short quiz to assess your comprehension. After that, you will play a game.

The Maasai are an ethnic group living in the East African countries of Kenya and Tanzania. They live mainly in and around the Great Rift Valley, which runs north and south through eastern Africa. They speak a language called Maa. Maa is also spoken by some very similar neighboring groups, such as the Samburu in northern Kenya and the Parakuyu in Tanzania.

While many ethnic groups in Kenya and Tanzania have experienced great cultural change in recent years, the Maasai are famous for how they have retained many of their traditional customs. Many Maasai still live in rural areas in small settlements organized around extended families. Maasai men are allowed to be married to more than one woman at a time. Each woman builds and maintains her own house. Many co-wives (women married to the same man) get along well with each other. When that is not the case, they might live in different settlements. Marriages are often arranged by family members rather than by the husband and wife themselves. Although unhappy brides, who are usually in their teens, often run home to their parents for a few days or weeks, most eventually return to their husbands, and divorce is rare.

The Great Rift Valley is a region dominated by vast grasslands. The Maasai make use of this landscape by basing their economy on livestock. The main species they raise are cattle, goats, and sheep. They also raise camels in the drier parts of their range and keep donkeys as beasts of burden. Although these days many Maasai have received formal educations and have jobs, the Maasai economy is still based on livestock. Their diet is based on milk, meat, and sometimes blood from their animals. Some clothing, particularly for formal ceremonies such as weddings, is still made from animal hides, and they even use cow dung as a sort of plaster when building a house.

Not surprisingly, daily life is structured around the needs of the livestock. Cattle are typically herded by an older boy while sheep and goats may be herded by younger children. Very young children stay near their homes and help tend the lambs, kids (baby goats), and calves. Women care for children, fetch water and firewood, and also do some herding. Men also contribute to the livestock economy by supervising their herds and by taking charge of difficult, long-distance herding to special grazing sites, water sources, and salt licks. 
The importance of livestock is also reflected by the fact that many crucial points in life are marked by the consumption or exchange of specific kinds of livestock. For example, when a Maasai woman gives birth, it is traditional for a sheep to be slaughtered, cooked, and eaten by the family. Livestock are also used for important gifts. For example, when a man gets married he gives his father-in-law a cow and his mother-in-law a sheep. From that time onward, he will call his fatherin-law "cow-receiver" and his father will call him "cow-giver." Similarly, he will call his mother-in-law "sheep-receiver" and she will call him "sheep-giver."

Although Maasai are now involved in the worldwide market economy, the fact that until recently each Maasai family was responsible for its own subsistence meant that market economy principles such as buying, selling, and investment were not very important to them. Only occasionally would they trade with others for food and other goods.

However, raising livestock can be a risky endeavor. Droughts, which occur frequently in East Africa, kill many livestock. Livestock also succumb to a variety of diseases. As a result, a man who is wealthy one year might be poor the next. To help each other through hard times, Maasai form special relationships called osotua. The literal meaning of osotua is "umbilical cord," so by using it to refer to giftgiving relationships Maasai are making a metaphorical connection between such relationships and the life-giving relationship between a mother and her child. Strictly speaking, osotua refers only to human umbilical cords, not those of animals, so its metaphorical use also reflects the especially human quality of such relationships.

Osotua relationships are some of the most important ties that Maasai have with each other, and osotua as a principle is one of the cornerstones of Maasai social life. Osotua relationships usually begin with a request for a gift or a favor. Such requests must arise from genuine need, and the amount requested must be limited to the amount that is actually needed. Gifts given in response to such requests must be given freely and from the heart, but, like the requests, they also must be limited to what is actually needed. To request more than you really need or to give more than is needed would both be violations of the basic principles of osotua.

Because the economy is based on livestock, many osotua gifts take the form of cattle, goats, or sheep, but virtually any good or service may serve as an osotua gift. For example, an osotua bond is formed between two men when one asks the other to be the best man at his wedding. Once osotua is established, it is eternal. It cannot be destroyed, even if the individuals who established the relationship die. In that case, it is passed on to their children. Osotua also does not follow any sort of schedule. Because requests should only arise from genuine need and gifts should be given only in response to such requests, a long time might pass between gifts, but the relationship will still exist.

Osotua is a reciprocal relationship in the sense that, once it is established between two people, each one has an obligation to help the other if asked to do so. However, actual osotua gifts may not be balanced, even roughly, over long periods 
of time. In fact, the flow of goods and services in a particular relationship might be mostly or entirely one-way, if that is where the need is greatest. Even in that situation, the relationship itself will endure.

Maasai give gifts in a variety of circumstances, and not all of them involve osotua. For example, some gifts are given without any request being made. Other kinds of gifts result in debt, meaning an obligation to repay the gift, rather than osotua. Osotua and debt are not at all the same. While osotua partners have an obligation to help each other in time of need, this is not at all the same as the debt one has when one has been lent something and must pay it back. Going along with the idea that osotua gifts do not repay debt, osotua gifts are not considered payments at all, and it is inappropriate to use the verb "to pay" (alak) when referring to them.

One Maasai man illustrated many of osotua's main features through a story about his own family. Many years ago when warfare was prevalent in Maasailand, his ancestor Kimbai was ambushed and killed by two men from an enemy group. One of Kimbai's killers then removed his warrior's belt (ntore) and wore it as a trophy.

After the fight, the killers visited another man and asked him for food, lodging, and medicine to treat their wounds. What the visitors did not know was that their host had an osotua bond with Kimbai. That man's wife recognized Kimbai's belt and deduced that the visitors had killed him. She and her husband slaughtered a sheep to feed the visitors, poisoned the food, killed the two visitors, and thus avenged Kimbai's death. This revenge killing was a form of osotua gift back to the dead Kimbai and, by extension, to his survivors. The belt was then returned to Kimbai's grandfather, and a bond of osotua has existed between the two families ever since.

That story demonstrates some of the main features of osotua relationships. For example, the gifts and services involved in such relationships are not always of livestock. Even a revenge killing can serve as an osotua gift, if that is what is needed. The bond created then lasts forever, being passed on to the children of those who originally created it.

More generally, the principle of osotua imbues respect, restraint, and a sense of responsibility in a way that non-osotua relationships do not. In the words of one Maasai man, "keiroshi": It is heavy. The principles of osotua are very closely related to another important principle in Maasai society: enkanyit, which translates as "respect." Maasai are expected to respect themselves and each other and to behave in a restrained and respectful manner. One Maasai man put it this way: "Osotua and enkanyit go together, osotua in the lead and enkanyit behind."

Maasai take the principles of osotua very, very seriously. When the principle of osotua is involved, they strictly adhere to the idea that requests for aid should only be made if they are genuinely needed and that gifts should only be given if needed and in the amount needed. Large or unrequested gifts, which Americans might see as signs of generosity and selflessness, would be considered rude and disrespectful if given within the context of Maasai osotua relationships. Within an 
osotua relationship it would also be disrespectful to say or imply that you expect a gift to be repaid. It would even be inappropriate to repay an osotua gift if no return gift is requested.

Reading comprehension questions:

1. Where do the Maasai live?
a. Kenya and Tanzania
b. Mozambique
c. Somalia
d. Lake Rudolf

2. In which type of landscape do the Masaai live?
a. high desert
b. vast grasslands
c. coastal sage scrub
d. none of the above

3. The Masaai sometimes build their homes from
a. adobe
b. straw
c. small stones
d. cow dung

4. Why is raising livestock such a risky proposition for the Masaai?
a. droughts may kill the livestock
b. livestock may die from disease
c. livestock may run away
d. A and B

5. What does osotua literally mean?
a. cattle, goats, or sheep
b. gift
c. umbilical cord
d. wattle and daub hut

6. How long do osotua relationships last?
a. forever
b. until the conclusion of the rainy season
c. 3 years at most
d. until the debt has been repaid

7. Under the principles of osotua, is it ever okay to ask for more than is needed?
a. yes, it would be considered insulting to ask only for what is needed
b. yes, but only if the man has more than one wife
c. no, it is never okay
d. yes, but only when there are livestock involved 
8. If someone receives an osotua gift, when should he give something in return?
a. after the appropriate waiting period has elapsed
b. only if his osotua partner asks him for a return gift
c. immediately; gifts should be exchanged simultaneously
d. never; osotua gift giving goes only in one direction

9. In which of the following ways could an osotua relationship be established?

a. through inheritance: a child could be born into an osotua relationship established by his parent

b. with a request for a gift or a favor

c. through serving as someone's best man at a wedding

d. all of the above

10. Once an osotua relationship has been established, how much should be given?
a. only as much as requested
b. slightly less than a day's wage
c. as much as one can afford
d. usually $50 \%$ of the total debt

(2) The text used for the dummy framing

\section{The Earth's atmosphere: A brief introduction}

This short presentation will familiarize you with the basic features of the Earth's atmosphere. After reading it, you will take a short quiz to assess your comprehension. After that, you will play a game.

Gravity pushes the layers of air down to the Earth's surface. This push is called air pressure. Consequently, $99 \%$ of the total mass of the atmosphere is below 32 kilometers.

Like all fluids (gases and liquids), the air exerts a pressure on everything within and around it, although we are not aware of it. Pressure is a force, or weight, exerted on a surface per unit area, and is measured in Pascals (Pa). The pressure exerted by a kilogram mass on the Earth' s surface is approximately $10 \mathrm{~Pa}$. The pressure exerted by the whole atmosphere on the Earth' s surface is approximately 100,000 Pa.

Usually, atmospheric pressure is quoted in millibars (mb). $1 \mathrm{mb}$ is equal to 100 $\mathrm{Pa}$, so standard atmospheric pressure is about $1000 \mathrm{mb}$. In fact, actual values of atmospheric pressure vary from place to place and from day to day. At sea level, commonly observed values range between $970 \mathrm{mb}$ and $1040 \mathrm{mb}$. Because pressure decreases with altitude, pressure observed at various stations must be adjusted to the same level, usually sea level.

Sometimes, atmospheric pressure is quoted in millimeters, centimeters or inches of mercury. This older form of measurement is related to the traditional 
method of measuring atmospheric pressure using a mercury barometer. Typical sea level atmospheric pressure is $76 \mathrm{~cm}$ mercury $(\mathrm{Hg})$ or 30 inches.

Variations in atmospheric pressure lead to the development of winds, which play a significant role in shaping our daily weather.

In addition, the Earth' s atmosphere is full of energy, which drives the world' $\mathrm{s}$ weather and shapes the climates. Over the longer term, changes to this energy can bring about variations in climate.

All bodies emit energy in the form of electromagnetic radiation. Light is a form of electromagnetic radiation. So are infrared heat, ultraviolet radiation, radio waves and $\mathrm{x}$-rays. The type of radiation emitted by a body depends upon its temperature. Hotter objects release more energetic radiation. The Sun, for example, emits visible light and ultraviolet energy. The Earth and its atmosphere, being much cooler, emit radiation in the infrared part of the spectrum. Living things, including humans, also emit radiation in the infrared part of the spectrum. This energy is known as heat energy.

When the Earth receives (light and ultraviolet) energy from the Sun, much of it is absorbed either by the atmosphere or at the Earth's surface. The Earth re-radiates (infrared) energy back to space, such that there is a balance between incoming energy from the Sun and outgoing energy from the Earth. This global energy balance maintains a fairly even temperature at the surface of the Earth.

Of course, there are differences in temperature between different parts of the world, due to the different amounts of received sunlight. Regions nearer the equator receive much more energy than regions nearer the poles, and are consequently much warmer. These differences in surface temperature create flows of energy within the Earth's atmosphere itself, which are the driving forces behind the world's weather.

Gases and aerosols in the Earth's atmosphere affect the transfer of energy to and from the planet. The greenhouse gases absorb a lot of infrared energy that is trying to escape to space, and heat up the planet. For this reason, the Earth is on average $33^{\circ} \mathrm{C}$ warmer than the moon, which is a similar distance from the Sun. This natural warming process is called the greenhouse effect. Gases and aerosols in the atmosphere scatter incoming sunlight in all directions. Blue light is scattered the most, which is why the sky appears blue during the daytime. Different parts of the Earth's surface also affect the transfer of energy. Polar regions covered in white snow and ice are much more reflective than darker areas of the planet, and proportionally less sunlight is absorbed there.

The atmosphere is composed of several layers, each defined because of the various phenomena which occur within the layer. These transitions are gradual, and most heights and measurements mentioned below refer to the average area of transition from one layer to another. Four distinct layers have been identified using thermal characteristics (temperature changes), chemical composition, movement, and density. Each of the layers are bounded by "pauses" where the maximum changes in these characteristics occur. 


\section{The Troposphere}

Oxygen and nitrogen make up the majority of the gases in the Earth's atmosphere, even at much higher altitudes. But it is the lowest level of Earth's atmosphere where the right mixture works to support life. Here, living things are also free from the radiation showers which flow down through most of the Earth's atmosphere.

Compared to the rest of the atmosphere, the troposphere is a tiny layer, extending at most ten miles $(16 \mathrm{~km})$ up from the Earth's surface. Within this small layer almost all of our weather is created - the short term changes in temperature, wind, pressure, and moisture that we experience as part of our daily lives. The lower altitudes are the warmest part of the troposphere, in part because the Earth's surface absorbs solar radiation and transfers this heat to the air. Generally, as altitude increases, temperature decreases steadily. But the Earth's topography can cause some lower regions in the troposphere to experience temperature inversions, where temperature actually increases with altitude. Towards the top of the troposphere temperatures fall to an average low of $-70^{\circ} \mathrm{F}\left(-57^{\circ} \mathrm{C}\right)$ and wind speeds increase significantly, making the top of the troposphere an extremely cold and windy place.

\section{The Stratosphere}

The gradual change from the troposphere to the stratosphere begins at approximately 7 miles $(11 \mathrm{~km})$ high. The temperature in the lower stratosphere is extremely stable and cold at $-70^{\circ} \mathrm{F}\left(-57^{\circ} \mathrm{C}\right)$. Here, strong winds occur as part of defined circulation patterns. High cirrus clouds sometimes form in the lower stratosphere, but for the most part there are no significant weather patterns in the stratosphere. From the middle of the stratosphere and up, the temperature pattern undergoes a sudden change, sharply increasing with height. Much of this temperature change is due to increasing levels of ozone concentration which absorbs ultraviolet radiation. The temperature can reach a balmy $65^{\circ} \mathrm{F}\left(18^{\circ} \mathrm{C}\right)$ in the upper stratosphere near an altitude of 25 miles ( $40 \mathrm{~km})$ high.

\section{The Mesosphere}

25 miles $(40 \mathrm{~km})$ above the Earth's surface marks the transition to the mesosphere. In this layer, temperature once again begins to fall as altitude increases, to temperatures as low as $-225^{\circ} \mathrm{F}\left(-143^{\circ} \mathrm{C}\right)$ near its top, 50 miles $(81 \mathrm{~km})$ above the Earth. Such extreme cold allows the formation of so-called noctilucent clouds, thought to be made of ice crystals clinging to dust particles.

\section{The Thermosphere}

The transition from the mesosphere to the final thermosphere layer begins at a height of approximately 50 miles $(81 \mathrm{~km})$. The thermosphere receives its name 
from the return to increasing temperature which can reach a staggering $3,600^{\circ} \mathrm{F}$ $\left(1982^{\circ} \mathrm{C}\right)$. These extreme temperatures are caused by the absorption of the sun's shortwave ultraviolet radiation. This radiation penetrates the upper atmosphere, stripping atoms of their electrons and giving them a positive charge. Electrically charged atoms build up to form a series of layers within the thermosphere. These charged layers are often referred to as the ionosphere, which deflects some radio signals. Before the modern use of satellites, this deflection by the ionosphere was essential for long distance radio communication. Today, radio frequencies which pass through the ionosphere unaffected are chosen for satellite communication.

Beautiful auroras, also known as the Northern and Southern lights, occur in the thermosphere when solar flares from the sun create magnetic storms near the poles. These magnetic storms strip atoms of their electrons. Brilliant green and red light is emitted when the electrons rejoin the atom, returning the atoms to their original state.

Energy from these electrically charged particles is converted into light, forming visible glows, rays, arcs, bands and veils. The charged particles are attracted by the Earth's magnetic field. Near the magnetic poles, the Earth's magnetic field becomes much stronger. Consequently, it is nearer the magnetic poles that the auroras are most frequently witnessed.

The power of auroras depends mostly on the strength of the solar wind. During an intense solar storm, the wind can intensify very strongly, and auroras may be seen at lower latitudes further from the magnetic poles. Every 11 years, at the peak of the sunspot cycle there is an increase in intensity of the solar wind, and with it, an increase in frequency and intensity of auroral displays.

Auroras occur in both the Northern and Southern Hemispheres. In the Northern Hemisphere, the display is known as the aurora borealis, or northern lights. In the Southern Hemisphere, it is called the aurora australis, or southern lights. The term aurora polaris, polar lights, is a general name for both. Auroras are usually visible from within the Arctic or Antarctic circles - Antarctica, Greenland, Iceland and Northern regions of Canada, Alaska, Scandinavia and Russia. During times of more intense activity on the Sun, auroral storms can be viewed at lower latitudes such as northern Scotland and most of Norway, Sweden and Finland. Very rarely displays can be seen from northerly parts of Europe and the United States.

Even higher - above the auroras and the ionosphere - the gases of this final atmospheric layer begin to dissipate, until finally, several hundred miles above the Earth, they fade off into the depths of space.

Sources: This text combines quotations and paraphrasings from web sites maintained by Manchester Metropolitan University, the National Weather Service, and the Public Broadcasting System:

http://www.ace.mmu.ac.uk/eae/Atmosphere/Older/Pressure.html http://www.ace.mmu.ac.uk/eae/Atmosphere/Older/Energy.html http://www.ace.mmu.ac.uk/eae/Atmosphere/Older/Aurora.html http://www.srh.weather.gov/srh/jetstream/atmos/layers.htm 
Reading comprehension questions:

1. Which gases make up the majority of the earth's atmosphere?
a. oxygen and hydrogen
b. oxygen and helium
c. oxygen and nitrogen
d. oxygen and ozone

2. What causes the different temperatures of different parts of the world?
a. solar winds that begin at the equator
b. differences between amounts of received sunlight
c. the gravitational pull of Mercury
d. A and B

3. What causes the majority of the total mass of the atmosphere to be below 32 kilometers?
a. air pressure caused by gravity
b. ultraviolet energy from the sun
c. variations in temperature
d. the force of solar winds

4. Which of the following areas has the lowest (least) air pressure?
a. the bottom of the Atlantic Ocean
b. any area in the Gobi Desert
c. the top of Mount Everest
d. Salt Lake City, Utah

5. Why is the sky blue?
a. this remains one of the great mysteries of science
b. gases and aerosols in the atmosphere scatter blue light the most
c. air pressure causes light waves to expand upon entering the troposphere
d. water droplets in the thermosphere reflect the sun's rays

6. Almost all of our weather is created in the
a. thermosphere
b. mesosphere
c. troposphere
d. none of the above

7. What causes the intense heat of the upper stratosphere and the thermosphere?
a. the absorption of ultraviolet radiation
b. the presence of nitrogen
c. a thick layer of noctilucent clouds
d. the short distance to earth

8. In the atmosphere, what happens to air temperature as altitude increases?
a. it always increases
b. it always decreases
c. it remains the same
d. it may either increase or decrease 
9. Where would be a good place to see an aurora?
a. Iceland
b. Africa
c. Antarctica
d. A and C

10. Which factor influences the intensity of aurora displays?
a. magnetic storms near the poles
b. the strength of the solar wind
c. the altitude of the observer
d. all of the above

\section{ACKNOWLEDGMENTS}

Funding for this project was provided by Rutgers' Center for Human Evolutionary Studies. We thank Ginny Caputo, Kaitlin Coulter, Rolando de Aguiar, Beth L. Leech, Chris Redmond, and Kristina Tee for their help.

\section{REFERENCES}

Bacharach, M. (2006): Beyond Individual Choice: Teams and Frames in Game Theory. Princeton, NJ: Princeton University Press.

BARr, A. (2004): Kinship, familiarity, and trust: An experimental investigation. In: Henrich, J. Boyd, R., Bowles, S., Camerer, C. Fehr, E. \& Gintis, H. (eds.): Foundations of Human Sociality. Oxford: Oxford University Press, pp. 305-334.

Bartlett, F. C. (1932): Remembering: A Study in Experimental and Social Psychology. Cambridge: Cambridge University Press.

BAteson, G. (1972): Steps to an Ecology of Mind. New York: Ballantine Books.

BiCCHIERI, C. (2006): The Grammar of Society: The Nature and Dynamics of Social Norms. Cambridge: Cambridge University Press.

Boyd, R. \& Richerson, P. (1985): Culture and the Evolutionary Process. Chicago: University of Chicago Press.

Burnham, T., McCABE, K. \& SMith, V.L. (2000): Friend-or-foe intentionality priming in an extensive form trust game. Journal of Economic Behavior and Organization, 43, 57-73.

Cronk, L. (1989): Low socioeconomic status and female-biased parental investment: The Mukogodo example. American Anthropologist, 91, 414-29.

Cronk, L. (1999): That Complex Whole: Culture and the Evolution of Human Behavior. Boulder, CO: Westview Press.

CRONK, L. (2000): Female-biased parental investment and growth performance among the Mukogodo. In: Cronk, L., Irons, W. \& Chagnon, N. (eds): Adaptation and Human Behavior: An Anthropological Perspective. Hawthorne, NY: Aldine de Gruyter, pp. 203-221.

Cronk, L. (2004): From Mukogodo to Maasai: Ethnicity and Cultural Change in Kenya. Boulder, CO: Westview Press.

CRONK, L. (2007): The influence of cultural framing on play in the trust game: A Maasai example. Evolution and Human Behavior, 28, 352-358. 
D’ANDRADE, R.G. (1992): Schemas and motivation. In: D’Andrade, R.G., Strauss, C. (eds): Human Motives and Cultural Models. Cambridge: Cambridge University Press, pp. 23-44.

ELLIOTT, C.S. \& HAYWARD, D.M. (1998): The expanding definition of framing and its particular impact on economic experimentation. Journal of Socio-Economics, 27, 229-243.

ENSMINGER, J. (2000): Experimental economics in the bush: Why institutions matter. In: Ménard, C. (ed): Institutions, Contracts and Organizations: Perspectives from the New Institutional Economics. Cheltenham, UK: Edward Elgar, pp. 158-171.

ENSMingER, J. (2004): Market integration and fairness: Evidence from ultimatum, dictator, and public goods experiments in East Africa. In: Henrich, J., Boyd, R., Bowles, S., Camerer, C., Fehr, E. Gintis, H. (eds): Foundations of Human Sociality. Oxford: Oxford University Press, pp. 356-381.

Gigerenzer, G., Todd, P.M. \& the AbC Research Group (2000): Simple Heuristics That Make Us Smart. New York: Oxford University Press.

GINTIS, H. (2007): A framework for the integration of the behavioral sciences. Behavioral and Brain Sciences, 30, 1-61.

Hagen, E.H., and Hammerstein, P. (2006): Game theory and human evolution: A critique of some recent interpretations of experimental games. Theoretical Population Biology, 69, 339-348.

HeINTz, C. (2005): The ecological rationality of strategic cognition. Behavioral and Brain Sciences, 28:825-826.

Henrich, J., Boyd, R., Bowles, S., CAmerer, C., Fehr, E. \& Gintis, H. (eds) (2004): Foundations of human sociality: Economic experiments and ethnographic evidence from fifteen small-scale societies. Oxford: Oxford University Press.

Hertwig, R. \& Ortmann, A. (2001): Experimental practices in economics: A methodological challenge for psychologists? Behavioral and Brain Sciences, 24, 383-451.

LALAND, K.N. \& WiLliams, K. (1998): Social transmission of maladaptive information in the guppy. Behavioural Ecology, 9, 493-499.

LESOROGOL, C.K. (2004): Experimental and ethnographic evidence for the effects of land privatization and market integration on trust and cooperation among Kenyan pastoralists. Paper presented at the annual meeting of the International Society for New Institutional Economics.

LESOROGOL, C.K. (2007): Bringing norms in: The role of context in experimental dictator games. Current Anthropology, 48, 920-926.

ORNE, M.T. (1962): On the social psychology of the psychological experiment: With particular reference to demand characteristics and their implications. American Psychologist, 17, 776783.

Pillutla, M.M. \& CHEN, X.-P. (1999): Social norms and cooperation in social dilemmas: The effects of context and feedback. Organizational Behavior and Human Decision Processes, 78, 81-103.

ReAder, S.M., Bruce, M.J. \& ReBers, S. (2007): Social learning of novel route preferences in adult humans. Biology Letters, 4, 37-40.

Schelling, T.C. (1960): The Strategy of Conflict. Cambridge, MA: Harvard University Press.

Sugden, R. (1993): Thinking as a team: Towards an explanation of non-selfish behavior. Social Philosophy and Policy, 10, 69-89.

Tracer, D. (2003): Selfishness and fairness in economic and evolutionary perspective: An experimental economic study in Papua New Guinea. Current Anthropology, 44, 432-38.

TVersky, A. \& Kahneman, D. (1981): The framing of decisions and the psychology of choice. Science, 211, 453-458.

VAN HuYCK, J.B., BATTALIO, R.C. \& RANKIN, F.W. (1995): On the origin of convention: Evidence from coordination games. Economic Journal, 107, 576-596. 